\title{
In Vitro Antileishmanial Activity of Helianthus annuus and Pulicaria crispa (Asteraceae)
}

\author{
Mohamed $\mathrm{M}^{1 *}$, Ahmed $\mathrm{MM}^{2}$, Elwaleed $\mathrm{EH}^{3}$, Walaa $\mathrm{SE}^{2}$ and Mahgoub $\mathrm{SE}^{3}$
}

${ }^{1}$ Department of Pharmacognosy, Faculty of Pharmacy, International University of Africa, Sudan

${ }^{2}$ Department of Immunology and Clinical Pathology, Institute of Endemic Diseases, University of Khartoum, Sudan

${ }^{3}$ Department of Pharmacognosy, Faculty of Pharmacy, Omdurman Islamic University, Sudan

\begin{abstract}
Leishmaniasis which is a neglected tropical disease is a global health problem. The treatment options are limited. They are either toxic or expensive. This study was conducted to test some medicinal plants belonging to Asteraceae family against Leishmania donovani promastigotes. Five plants have been selected: Helianthus annuus leaves, Pulicaria crispa aerial parts, Geigeria alata aerial parts, Acanthospermum hispidum aerial parts and Sonchus oleraceus leaves. $H$. annuus and $P$. crispa petroleum ether and chloroform extracts showed significant antileishmanial activity at $50 \mathrm{\mu g} / \mathrm{mL}$ in the general screening test, whereas the other three plant extracts showed significant antileishmanial activity in only one solvent system. $H$. annuus and $P$. crispa were further tested at doses range of $50,25,12.5,6.25$ and $3.125 \mu \mathrm{g} / \mathrm{mL}$. The $\mathrm{IC}_{50}$ for petroleum ether and chloroform extracts of $H$. annuus were $4.5 \mathrm{and} 3 \mu \mathrm{g} / \mathrm{mL}$ respectively. While the $\mathrm{IC}_{50}$ for petroleum ether and chloroform extracts of $P$. crispa were 4.9 and $3.75 \mu \mathrm{g} / \mathrm{mL}$ respectively. Thin layer chromatography for the active extracts of $H$. annuus and $P$. crispa has revealed the high similarity in their chemical composition which explains the similarity of their antiparasitic activity.
\end{abstract}

Keywords: Asteraceae; Antileishmanial activity; Leishmania donovani promastigotes; Helianthus annuus; Pulicaria crispa

\section{Introduction}

Leishmaniasis is one of the neglected tropical diseases which is widely distributed parasitic disease, it is caused by the protozoan of the genus Leishmania [1]; also, it is regarded as a major public health problem with high incidence of morbidity and mortality in Africa, Asia and Latin America [2].

According to WHO estimates, approximately 200,000 to 400,000 visceral leishmaniasis (VL) cases and 700,000 to 1.2 million cutaneous leishmaniasis (CL) cases occur each year; more than $90 \%$ of global VL cases occur in just six countries, namely India, Bangladesh, Sudan, South Sudan, Brazil and Ethiopia. Cutaneous leishmaniasis is more widely distributed, with about two-thirds of cases occurring in three regions, the Americas, the Mediterranean basin and Western Asia; the ten countries with the highest estimated cases are Afghanistan, Algeria, Colombia, Brazil, Iran, Syria, Ethiopia, Sudan, Costa Rica and Peru, altogether account for 70 to $75 \%$ of global estimated CL incidence [3].

Sudan is one of the countries which suffered and still suffering from leishmaniasis. Epidemiological studies in Sudan showed that both $L$. major and $L$. donovani are the main causative organisms of CL and VL respectively [4,5]. Also, Sudan is characterized by the presence of Post Kala- azar Dermal Leishmaniasis (PKDL) which is the complicated form of VL; it is developed from about $50 \%$ of patients who recovered from VL [6-8]. PKDL patients may play an important role in transmission and are presumed to be the cause of severe outbreaks after periods of low transmission [9].

Recently, treatment of both VL and CL depends on limited chemotherapeutic agents, some of them were obtained from natural products (like amphotericin B), and these limited drugs are either toxic, expensive, need parenteral administration or become useless due to parasite resistance [10]. Therefore, screening for new drugs with potent leishmanicidal activity is highly recommended, as most new developed drugs are still originated from natural sources [11].

Helianthus annuus L. is widely distributed plant which is cultivated mainly for the production of edible oil from its seeds. It represents the second most important edible oil in the world. Traditionally, it is used as anti-inflammatory, anti-pyretic, diuretic, renal disorders, emollient, expectorant, astringent, anti-asthma, disinfectants and vermifuge purposes [12].

Pulicaria crispa L. is also widely distributed over the world especially in arid and semi-arid areas, it has many traditional uses which are used for treatment of various ailments, the most important uses are in treatment of some heart diseases, gastro intestinal disorders, antibacterial, antifungal, anti-inflammatory and antiepileptic activities. Also, it possesses high antioxidant activity [13].

\section{Materials and Methods}

\section{Plant materials}

The plants were collected from different regions in Sudan from July 2012 to February 2013 (Table 1). They were identified and authenticated in Medicinal and Aromatic Plants Research Institute, National Center for Research in Khartoum.

\section{Extraction process}

The plants were shade dried and powdered; then they were extracted successively with petroleum ether, chloroform and methanol by soxhlet apparatus. The extracts were dried under reduced pressure and the yield percentages were calculated with the reference to dry powders. The extracts were kept in well closed containers in the refrigerator at $4^{\circ} \mathrm{C}$.

*Corresponding author: Mohamed Mirghani, Department of Pharmacognosy, Faculty of Pharmacy, International University of Africa, Sudan, Tel: +249123854142; E-mail: mohamedmirghani1@gmail.com

Received April 23, 2017; Accepted May 03, 2017; Published May 08, 2017

Citation: Mohamed M, Ahmed MM, Elwaleed EH, Walaa SE, Mahgoub SE (2017) In Vitro Antileishmanial Activity of Helianthus annuus and Pulicaria crispa (Asteraceae). Nat Prod Chem Res 5: 268. doi: 10.4172/2329-6836.1000268

Copyright: (c) 2017 Mohamed M, et al. This is an open-access article distributed under the terms of the Creative Commons Attribution License, which permits unrestricted use, distribution, and reproduction in any medium, provided the original author and source are credited. 


\begin{tabular}{|c|c|c|c|}
\hline No. & Plant (Latin name) & Local name & Source \\
\hline $\mathbf{1}$ & Helianthus annuus leaves & Zahrat Elshams & Taghar, Rabul \\
\hline $\mathbf{2}$ & Pulicaria crispa (aerial parts) & Gudgad & Omdurman \\
\hline $\mathbf{3}$ & Geigeria alata (aerial parts) & Herab Elhawsa & Om-rowaba (North Kordofan) \\
\hline $\mathbf{4}$ & Acanthospermum hispidum (aerial parts) & Elmoleata & Shambat (Khartoum North) \\
\hline $\mathbf{5}$ & Sonchus oleraceus (aerial parts) & Darfur) \\
\hline
\end{tabular}

Table 1: The plants and their sources

\section{Parasite culture}

Leishmania donovani parasite was obtained from The Institute of Endemic Diseases, University of Khartoum. The parasite was isolated from visceral leishmaniasis Sudanese patient in NNN media. The cultures were transferred into $50 \mathrm{ml}$ tissue culture flasks and cultured in M-199 medium supplemented with 10-12\% Fetal Calf Serum (FCS) and 100 units of benzyl penicillin and streptomycin. The parasites were maintained in this medium and the flasks were examined every two days for the growth and contamination. The parasites (at stationary phase) were routinely sub cultured when good growth was observed almost every three days.

\section{Preparation of the plant extracts for antileishmanial activity screening}

Twenty mg from each plant extract was taken and dissolved with minimum amount of DMSO (almost $0.2 \mathrm{~mL}$ ), and then the volume was completed to $1 \mathrm{~mL}$ by adding M-199 complete media, to prepare 20 $\mathrm{mg} / \mathrm{mL}$ stock solution. Different concentrations were prepared for the general antileishmanial screening up to a final concentration of $50 \mu \mathrm{g} /$ $\mathrm{mL}$. Promising extracts will be further tested at lower concentrations.

\section{Antileishmanial activity}

Antileishmanial activity screening was carried according to Attaur-Rahman et al. method [14]. In a 96 well micro titer plate, $90 \mu \mathrm{L}$ of the parasite culture with $\left(2 \times 10^{6} \mathrm{~L}\right.$. donovani promastigotes $\left./ \mathrm{ml}\right)$ were taken into each well. $10 \mu \mathrm{L}$ of each plant extract with final concentration of $50 \mu \mathrm{g} / \mathrm{mL}$ were put in each well and mixed well. Amphotericin B was set as positive control with final concentration of $10 \mu \mathrm{g} / \mathrm{mL}$, while 10 $\mu \mathrm{L}$ of M-199 complete media containing 5\% DMSO was set as negative control. The plate was incubated inside the incubator at $25^{\circ} \mathrm{C}$. Parasites counting were done after 48 hours of incubation to determine the inhibition percentages; also, morphology and motility of the parasites were checked. Highly active extracts of $H$. annuus and $P$. crispa were further tested at concentrations $(50,25,12.5,6.25$ and $3.125 \mu \mathrm{g} / \mathrm{mL})$ in order to determine their $\mathrm{IC}_{50}$ which was obtained by using excel sheet.

\section{TLC profiling of $H$. annuus and $P$. crispa active extracts}

Petroleum ether and chloroform extracts of both $H$. annuus and $P$. crispa were subjected to TLC using precoated aluminum plates, several mobile phase systems were attempted, $n$-hexane: ethyl acetate (4:1) was found to be the most suitable mobile phase system which had showed good separation of the compounds, the plates were seen under UV light, exposed to iodine and finally were sprayed by vanillin-o- phosphoric acid as an indicator and heated in an oven at $110^{\circ} \mathrm{C}$ for 10 minutes.

\section{Preliminary phytochemical screening of $\boldsymbol{H}$. annuus and $P$. crispa}

The above plant powders were screened for the presence of different phytochemical groups. Various chemical tests were performed: flavonoids $(\mathrm{NaOH})$, anthraquinones (Borntrager's test), cyanogenic glycosides (sodium picrate paper), alkaloids (Mayer's, Wagner's and Dragendorff's), saponins (froth test), cardiac glycosides (Baljet's, Keller-Killiani's and Liebermann-Burchard's tests), steroids (Liebermann-Burchard's test), tannins $\left(\mathrm{FeCl}_{3}\right)$ and coumarins ( $\mathrm{NaOH}$ and fluorescence).

\section{Results and Discussion}

\section{Antileishmanial activity}

The results of the inhibition percentages for all plant extracts used in general antileishmanial screening test at $50 \mu \mathrm{g} / \mathrm{ml}$ are shown in Tables 2 and 3.

In general, nonpolar and moderately polar extracts were found to be more active than polar extracts, except $S$. oleraceus which exhibited the highest activity for methanol extract and low activity for petroleum ether and moderate activity for chloroform. Both $H$. annuus and $P$. crispa showed very strong activity for both petroleum ether and chloroform extracts, but with weak activity for methanol extracts. $G$. alata and A. hispidum showed very strong antileishmanial activity for chloroform extracts and moderate activity for petroleum ether extracts; in addition, the methanolic extract of $A$. hispidum has shown moderate antileishmanial activity.

Petroleum ether and chloroform extracts of both $H$. annuus and $P$. crispa were tested in dose range of $50,25,12.5,6.25$ and $3.125 \mu \mathrm{g} / \mathrm{mL}$ and the results are shown in Figures 1 and 2, reflecting that chloroform extract is more active for both species with slight differences in the results.

The $\mathrm{IC}_{50}$ for all extracts showed that $H$. annuus was more active than $P$. crispa, but the differences are relatively low. Moreover, according to excel sheet, about $23.5 \mu \mathrm{g} / \mathrm{mL}$ was the minimum concentration needed to cause $100 \%$ leishmanicidal activity and was seen in the chloroform extract of $H$. annuus (Figure 1); while about $47 \mu \mathrm{g} / \mathrm{mL}$ was, the minimum concentration needed to cause $100 \%$ leishmanicidal activity which was observed in the petroleum ether extract of $P$. crispa (Figure 2). Generally, the active extracts of both species revealed that more than $90 \%$ of leishmanicidal activity is exhibited between $20-50 \mu \mathrm{g} / \mathrm{mL}$.

\section{Thin layer chromatography}

The picture shows that there are some associated compounds in the two extracts for the two plants reflecting the convergence in the results. This means that these compounds have almost the same nucleus, may be identical (for the same plant) or may be much related (for the two plants).

Many previous studies proved that the antileishmanial activity of most plants belonging to Asteraceae family are attributed to terpenoidal compounds, these compounds like monoterpenes, sesquiterpenes, sesquiterpene lactones, diterpenes and triterpenes are very frequently present in Asteraceae plants and are mainly extracted via nonpolar solvents; the family Asteraceae species are reputed for their content of sesquiterpene lactones, a group of compounds with wide range of biological activities [15]. Our findings which are compatible with these findings depicted that the activity of these two plants mainly can be probably due to their content of sesquiterpene lactones. On the other 
Citation: Mohamed M, Ahmed MM, Elwaleed EH, Walaa SE, Mahgoub SE (2017) In Vitro Antileishmanial Activity of Helianthus annuus and Pulicaria crispa (Asteraceae). Nat Prod Chem Res 5: 268. doi: 10.4172/2329-6836.1000268

Page 3 of 5

\begin{tabular}{|c|c|c|c|c|}
\hline \multirow{2}{*}{ No. } & \multirow{2}{*}{ Plant } & & \multicolumn{2}{|c|}{ Inhibition \% } \\
\hline & & Petroleum ether & Chloroform & Methanol \\
\hline 1 & Helianthus annuus leaves & +++ & +++ & - \\
\hline 2 & Pulicaria crispa (aerial parts) & +++ & +++ & - \\
\hline 3 & Geigeria alata (aerial parts) & ++ & +++ & + \\
\hline 4 & Acanthospermum hispidum (aerial parts) & ++ & +++ & ++ \\
\hline 5 & Sonchus oleraceus leaves & + & ++ & +++ \\
\hline
\end{tabular}

(-): No or very weak activity; (+): Inhibition \% < 50\%; (++): Inhibition \% between 50-75\%; (+++): Inhibition \% $75 \%$

Table 2: General antileishmanial screening of the plant extracts.

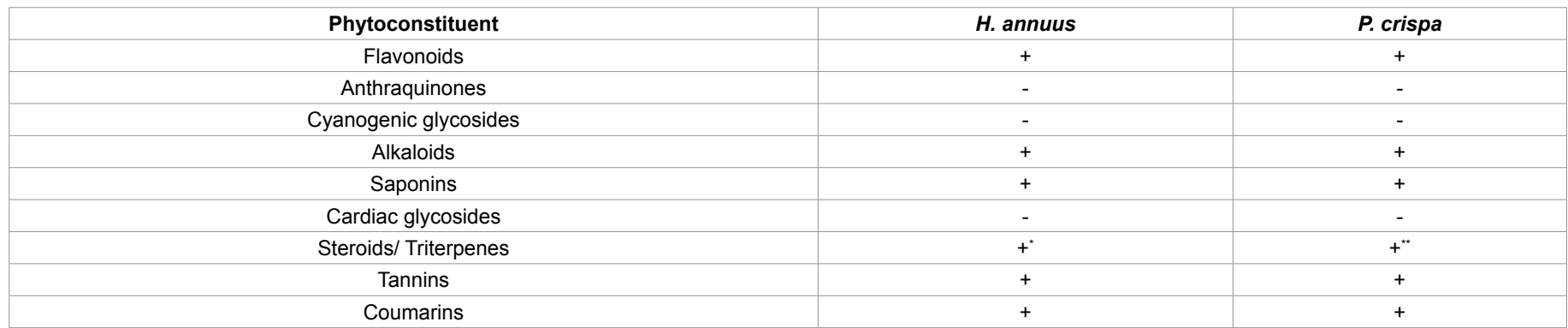

$(+)$ : present; (-): absent; $\left(^{*}\right)$ : green color; $\left(^{* *}\right)$ : pink color

Table 3: Preliminary phytochemical screening of $H$. annuus and $P$. crispa.

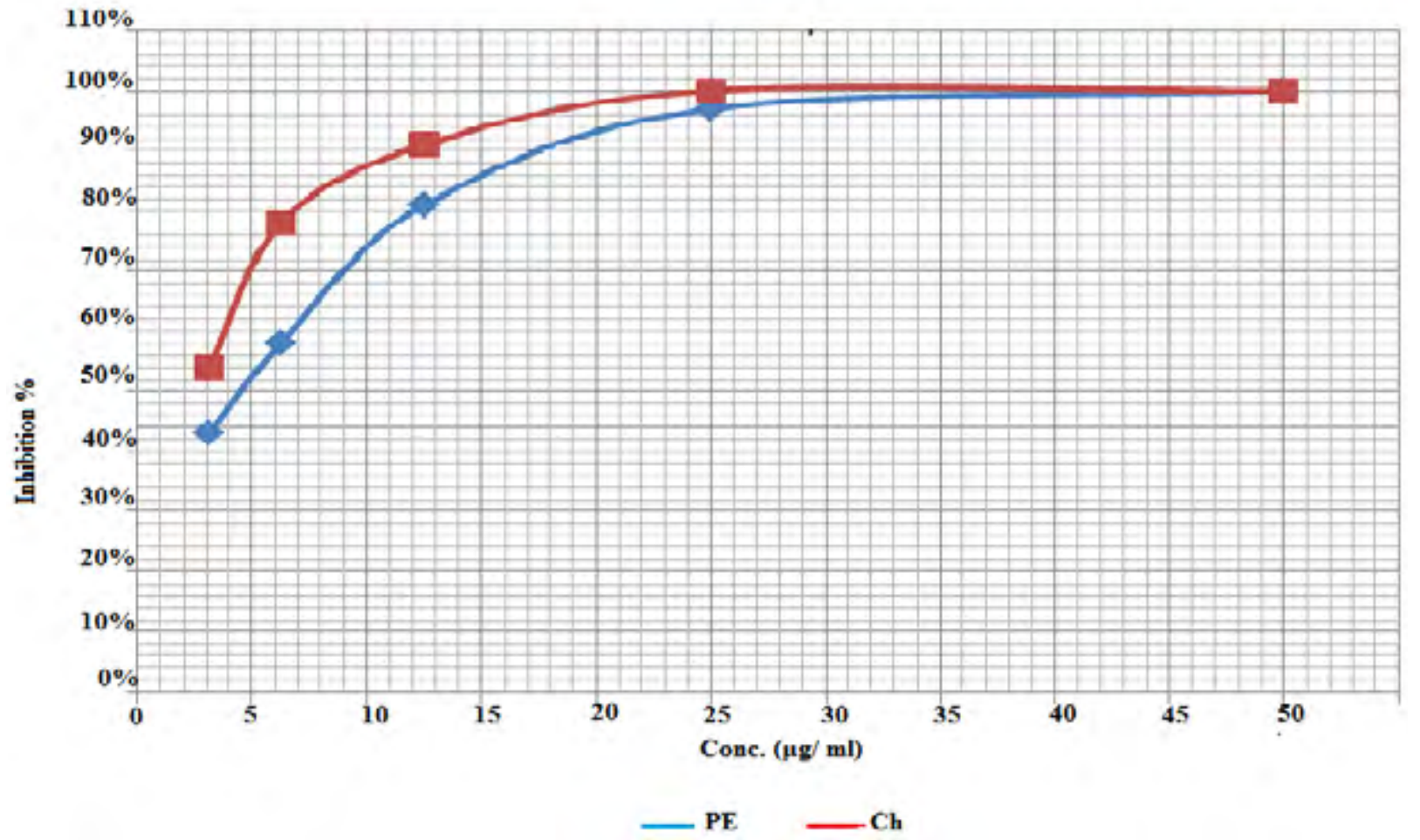

Figure 1: Inhibition percentage (Y- axis) versus concentration in $\mu \mathrm{g} / \mathrm{mL}$ (X- axis) of petroleum ether (PE) and chloroform (Ch) extracts of $H$. annuus leaves; the IC ${ }_{50}$ of the chloroform extract is about $3 \mu \mathrm{g} / \mathrm{mL}$, while the $\mathrm{IC}_{50}$ of the petroleum ether extract is about $4.5 \mu \mathrm{g} / \mathrm{mL}$.

side, the activity of $S$. oleraceus (methanolic extract) may be attributed to flavonoids (or any other phenolic compounds) which are also widely distributed in Asteraceae family [16].

\section{Phytochemical screening}

Both species have shown high similarity in their content of secondary phytochemical constituents; the only difference observed was in Liebermann- Burchard's test which is used for detection of steroids and triterpenes, $H$. annuus showed the domination of green color which indicates the presence of steroidal nucleus, while $P$. crispa showed the domination of pink color which indicates the presence of triterpenes; so, these observations agree with previous studies [12,13]. 
Citation: Mohamed M, Ahmed MM, Elwaleed EH, Walaa SE, Mahgoub SE (2017) In Vitro Antileishmanial Activity of Helianthus annuus and Pulicaria crispa (Asteraceae). Nat Prod Chem Res 5: 268. doi: 10.4172/2329-6836.1000268
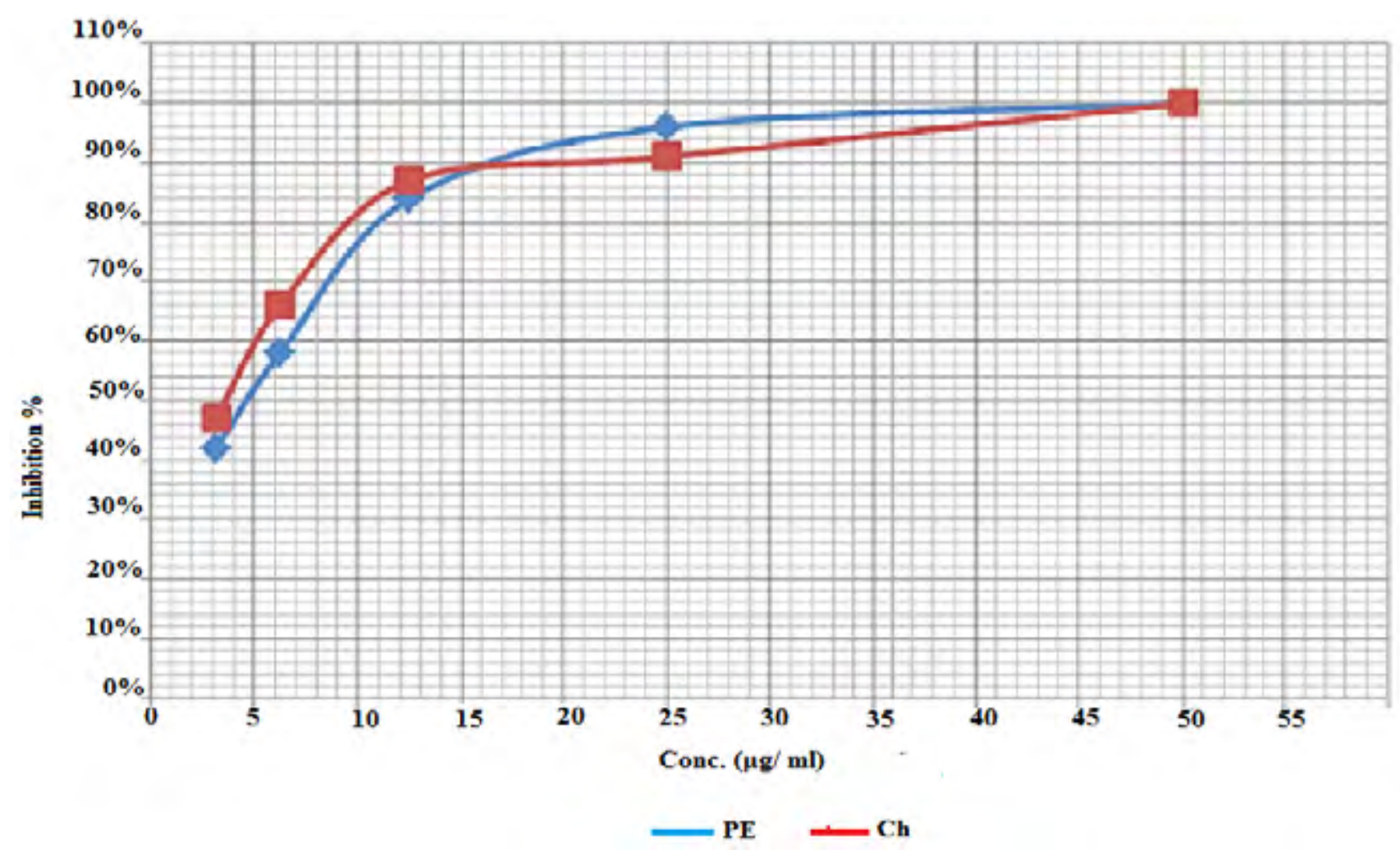

Figure 2: Inhibition percentage (Y- axis) versus concentration in $\mu \mathrm{g} / \mathrm{mL}$ (X-axis) of petroleum ether (PE) and chloroform (Ch) extracts of $P$. crispa; the IC ${ }_{50}$ of chloroform extract is about $3.75 \mu \mathrm{g} / \mathrm{mL}$, while the $\mathrm{IC}_{50}$ of petroleum ether extract is about $4.9 \mu \mathrm{g} / \mathrm{mL}$.
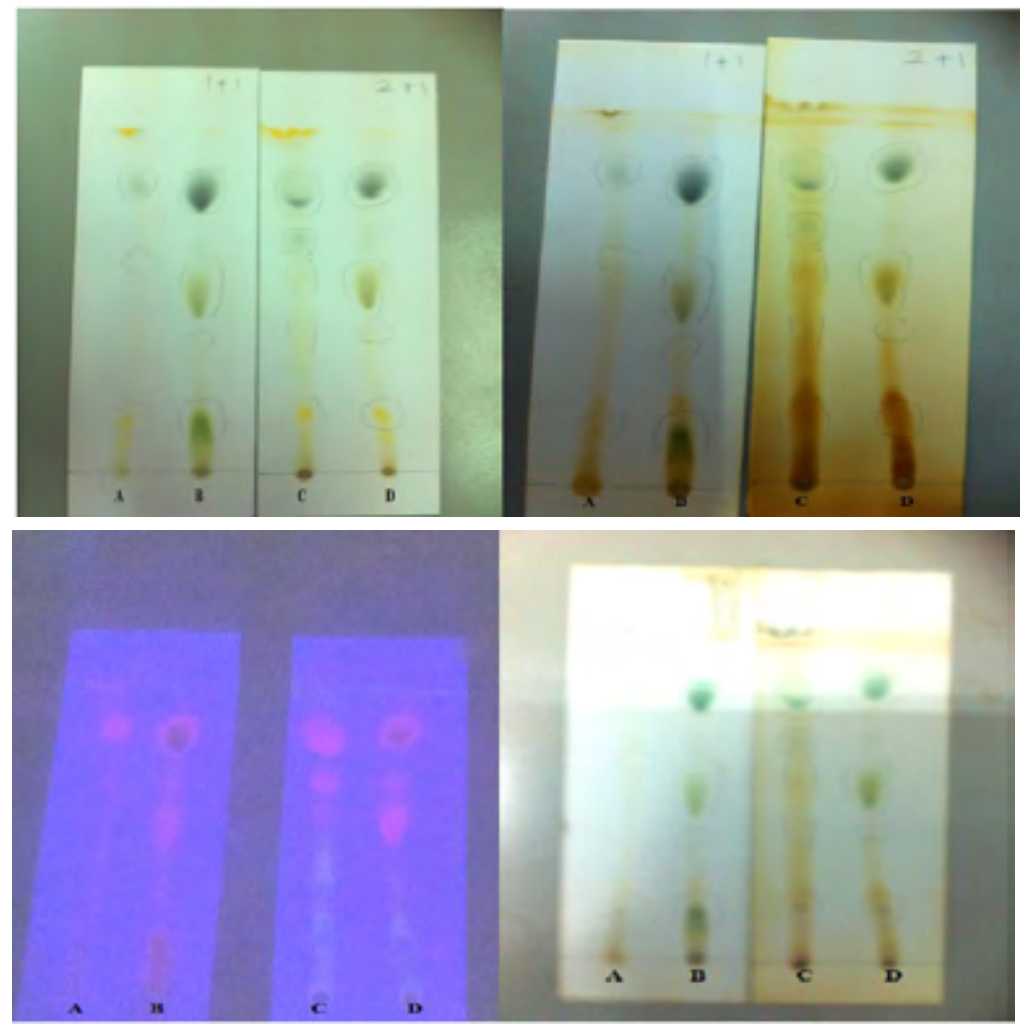

Figure 3: TLC profile of the active extracts: A, $H$. annuus petroleum ether extract; $\mathbf{B}, H$. annuus chloroform extract; C, $P$. crispa petroleum ether extract; $\mathbf{D}, P$. crispa chloroform extract. Upper left, original plates; Upper right, exposed to iodine; Lower left, seen under long UV light; Lower right, treated with vanillin-o-phosphoric acid and heated. 
This high similarity of phytochemical constituents in both species goes along with the results obtained from antileishmanial activity (Figure 3 ). Also, a part of similarity can be seen from the TLC profile.

\section{Conclusion}

The study explicit the importance of medicinal plants as a source of new lead compounds. $H$. annuus and $P$. crispa showed promising antileishmanial activity. Our future plan is to attempt fractionation to the active extracts, the fractions should again be tested which finally lead to structure elucidations of the active fractions. Also, we recommend testing the active extracts against $L$ donovani amastigotes, as amastigotes are the infective form of the parasite to humans.

\section{Acknowledgements}

The authors are grateful to Mr. Salah Abdulgabbar, Dr. Omsalama Abdulmajid and Mr. Mohamed Hassan in International University of Africa, Faculty of Pharmacy, Department of Pharmacognosy for their great support during the run of this study.

\section{References}

1. Hotez PJ, Pecoul B (2010) "Manifesto" for advancing the control and elimination of neglected tropical diseases. PLoS Neglected Tropical Disease 4: e718.

2. Gurib-Fakim A, Mahomoodally MF (2013) African flora as potential sources of medicinal plants: Towards the chemotherapy of major parasitic and other infectious diseases - A review. Jordan Journal of Biological Sciences 6: 77-84.

3. World Health Organization (2012) Leishmaniasis: Epidemiology and access to medicines. WHO, Geneva, Switzerland.

4. Gaafar A, Elkadro AY, Theander TG, Permin H, Ismail A, et al. (1995) The pathology of cutaneous leishmaniasis due to Leishmania major in Sudan. American Journal of Tropical Medicine and Hygiene 52: 438-442.

5. El-Amin EM, Guizani I, Guerbouj S, Garmiccia M, Elhassan AM, et al. (2008) Identification of Leishmania donovani as a cause of cutaneous leishmaniasis in Sudan. Transactions of the Royal Society of Tropical Medicine and Hygiene 102: $54-57$.
6. Musa AM, Khalil EA, Raheem MA, Ziljlstra EE, Ibrahim ME, et al. (2002) The natural history of Sudanese post kala'azar dermal leishmaniasis: clinical immunological and prognostic features. Annals of Tropical Medicine and Parasitology 96: 765-772.

7. Zijlistra EE, Musa AM, Khalil EAG, Elhassan IM, Elhassan AM (2003) Postkala'azar dermal leishmaniasis. The Lancet Infectious Diseases 3: 87-98.

8. Ismail A, Fattah A, Gadir A, Theander TG, Kharazmi A, et al. (2006) Pathology of post kalaazar dermal leishmaniasis: a light microscopical, immunohistochemical and ultra-structural of study skin lesions and draining lymph nodes. Journal of Cutaneous Pathology 33: 778-787.

9. El-Hassan AM, Khalil EA (2001) Post kalaazar dermal leishmaniasis: does it play a role in the transmission of Leishmania donovani in the Sudan? Tropical Medicine and International Health 6: 743-744.

10. Croft SL, Olliaro P (2011) Leishmaniasis chemotherapy-challenges and opportunities. Clinical Microbiology and Infection 17: 1478-1483.

11. Tiuman TS, Santos AO, Ueda-Nakamura T, Dias BP, Nakamura CV (2011) Recent advances in leishmaniasis treatment. International Journal of Infectious Diseases 15: 525-532

12. Dwivedi A, Sharma GN (2014) A review on Heliotropism plant: Helianthus annuus L. Journal of Phytopharmacology 3: 149-155.

13. Ahmed IF, Aftab A, Gamal AS, Mohammed AS, Elmutasim OIA, et al. (2015) Pharmacognostical, antioxidant and anti-microbial studies of aerial part of Pulicaria crispa (Family: Asteraceae). Bulletin of Environment, Pharmacology and Life sciences 4: 19- 27.

14. Atta-ur-Rahman A, Choudhary MI, Thomsen WJ (2005) Bioassay Techniques for Drug Development. Harwood Academic Publishers, Singapore. Accessed on: January 2007.

15. Schmidt TJ, Khalid SA, Romanha AJ, Alves TM, Biavatti MW, et al. (2012) The potential of secondary metabolites from plants as drugs or leads as protozoan meglected diseases- part one. Current Medicinal Chemistry 19: 2128-2175.

16. Schmidt TJ, Khalid SA, Romanha AJ, Alves TM, Biavatti MW, et al. (2012) The potential of secondary metabolites from plants as drugs or leads against protozoan neglected diseases - Part II. Current Medicinal Chemistry 19: 2176-2228. 